\section{Calorimetric Analysis of Gerbera Flowers}

\author{
Kenneth R. Tourjee ${ }^{1}$, James Harding ${ }^{2}$, and Thomas G. Byrne ${ }^{3}$ \\ Environmental Horticulture Department, University of California, Davis, \\ CA 95616
}

Additional index words. Gerbera jamesonii, Composite, reflectance spectrophotometry, hue, value, chroma, CIELAB

\begin{abstract}
Ligule color of a Gerbera jamesonii H. Bolus ex Hooker population was analyzed with a reflectance spectrophotometer having a spectral capability of 400 to $700 \mathrm{~nm}$ and a cv $<3 \%$ for the variables hue, chroma, and value. The observations for each variable had a continuous distribution; these broad distributions are possibly bimodal. The repeatability of hue, chroma, and value, determined as the correlation between measurements made on plants in December and those made on the same plants the following April, are 0.83, 0.82 , and 0.86 , respectively. The phenotypic correlations between value and chroma, value and hue, and chroma and hue are $\mathbf{- 0 . 3 5}, \mathbf{0 . 7 3}$, and 0.11 , respectively. Some possible biochemical implications concerning the interaction of anthocyanin and carotenoid pigments are discussed. Reflectance spectroscopy and Commission International de l'Eclairage $1976\left(L^{*} a^{*} b^{*}\right)$ color space notation provide an objective and precise method for incorporating color into a recurrent selection program.
\end{abstract}

The study of flower color has played a pivotal role in understanding modes of inheritance throughout the history of genetics (Lawrence, 1950; Lawrence and Price. 1940 Onslow, 1925). These and more recent investigations (Ennos and Clegg, 1983; Epperson and Clegg, 1988; Ladd et al., 1984; Negi and Raghaven, 1990) defined flower color as a qualitative trait indicative of the presence of pigments in a biochemical pathway of a threeor four-gene system involving dominance and epistasis. However, Nieuwhof et al. (1988) described flower pigmentation in tulips as a quantitative trait that could be correlated with observed color classes.

Visual matching to a reference standard is used frequently to specify color. When a match has been obtained, the sample color is assigned to a class according to one of the many current color systems. The Munsell color system, for example, defines a three-dimensional color space based on the attributes hue, chroma, and value. Specifying these three attributes results in a color sample that is uniquely located in color space (Agoston, 1979).

Unfortunately, visual matching has not provided the precision necessary to describe adequately ligule color variation in Gerbera jamesonii (Composite). Interfering factors,

Received for publication 15 June 1992. Accepted for publication $21 \mathrm{Dec}$. 1992. Research conducted at Environmental Horticulture Dept., Univ. of California, Davis. Use of trade names does not imply endorsement of the products named nor criticism of similar ones not named. The cost of publishing this paper was defrayed in part by the payment of page charges. Under postal regulations, this paper therefore must be hereby marked advertisement solely to indicate this fact.

Graduate Student.

${ }^{2}$ Professor.

${ }^{3}$ Specialist, Emeritus, Agricultural Experiment Station. such as uncontrolled incident light and perceptual differences among observers, reduce the ability to discern small differences between classes. Assigning flower color in gerbera to discrete classes to determine its mode of inheritance has not resulted in Mendelian segregation ratios even when chromatographic analysis was used to identify pigments (Vandoni, 1977).

Reflectance spectroscopy provides an opportunity to study gerbera flower color as a continuous variable. This technique analyzes the spectrum of visible light reflected from a surface irradiated with a defined incident light, yielding an objective and precise method of color measurement. It has been used successfully in such diverse applications as matching soil samples (Fernandez and Schultze, 1987), measuring the skin color of apples (Malus domestica Borkh.) (Francis, 1952), and assessing papaya (Carica papaya L.) fruit maturity (Hayes et al., 1988). Most color data in the food science literature has been reported in the Hunter L, a, b color system (Francis, 1980). In vivo reflectance spectroscopy and the Commission International de l'Eclairage (CIELAB) color system are being used to quantify the color of peaches [Prunus persica (L.) Batsch] (T. Gradziel, personal communication) and strawberries (Fragaria $\times$ ananassa Duch.) (Shaw, 1991).

The purpose of this paper is to illustrate the use of a portable spectrophotometer to describe the phenotypic distribution of color attributes-hue, chroma, and value-in the Univ. of California, Davis, gerbera population (Harding et al., 1985); provide evidence that flower color can be treated as a quantitative trait in this population; and provide data concerning calorimetric precision.

\section{Davis gerbera population}

Gerbera is a heterozygous cross-pollinated crop that undergoes a marked reduction of vigor and productivity with inbreeding (Huang et al., 1992). The data in this study were obtained from 437 plants of generation 14 of the Davis gerbera population. The population was established as a variable gene pool in 1970 by crossing plants from many mixed seed lots (Byrne et al., 1977). Successive generations have been grown in the same glasshouse, with $\approx 10 \%$ of the progeny of each generation (i.e., $\approx 40$ plants) retained as parents of the next generation. Each generation, parents were randomly crossed in a factorial mating design ( $\mathrm{Yu}$ et al., 1991). Selection has been applied to various traits, such as flower yield and flower dry weight (Harding et al., 1991). However, direct selection has not been practiced on hue, chroma, or value.

Individual plants were grown in containers of a 1 sand : 1 peat : 1 redwood sawdust (by volume) mixture amended with dolomite to $\approx 6.5 \mathrm{pH}$. The plants were irrigated with a complete inorganic nutrient solution that included all macro- and micronutrients (e.g., $\mathrm{NH}_{4}^{+}, \mathrm{NO}_{3}^{-}, \mathrm{PO}_{4}^{-3}$, and $\mathrm{K}^{+}$at $10.64,182.79$, 42.19 , and $219.25 \mathrm{ppm}$, respectively). Air was maintained at 22 to $25 \mathrm{C}$ days and 16 to $19 \mathrm{C}$ nights. Seeds were planted singly in 5.0-ml plugs in 135-count plug trays on 6 June 1989, transplanted to 1.1-liter pots on 6 July, and again to 2.0-liter pots on 14 Aug. Final spacing was $10.76 \mathrm{plants} / \mathrm{m}^{2}$. Individual plants were evaluated for hue, chroma, and value at the cut-flower harvest stage (Drennan et al., 1986). Each plant was measured in Dec. 1989 and again in Apr. 1990.

\section{Flower color assay}

This study's data were obtained in terms of hue, chroma, and value according to CIELAB uniform color space (McLaren, 1976). Hue and chroma measure the selective absorption of visible light. Chroma describes the degree to which selective absorption occurs (i.e., color intensity), and hue describes which wavelengths are being absorbed (e.g., reds, yellows, greens, and blues). Value measures an achromatic property-the reflectance of total visible light from a surface (i.e., lightness). A thorough treatment of color theory can be found in, for example, Hunter and Harold (1987).

Measurements were obtained using the Agtron (Reno, Nev.) Colormet, a portable reflectance spectrophotometer with a spectral capability of 400 to $700 \mathrm{~nm}$ in 10-nm intervals, a 30-mm-diameter viewing area, and output in CIELAB notation. CIE illuminant D65 with a $10^{\circ}$ observer setting was used throughout the study. Individual measurements were made nondestructively. Gerbera flowers were assayed with the spectrophotometer's viewing area aligned on the radial axis of the flower against the ligules of the ray florets.

Before the study, two aspects of assay validation were examined. First, the cv (SD/ mean) for hue, chroma, and value were estimated based on 10 measurements of an individual flower. Second, repeatability was estimated from measurements made on plants in Decem- 

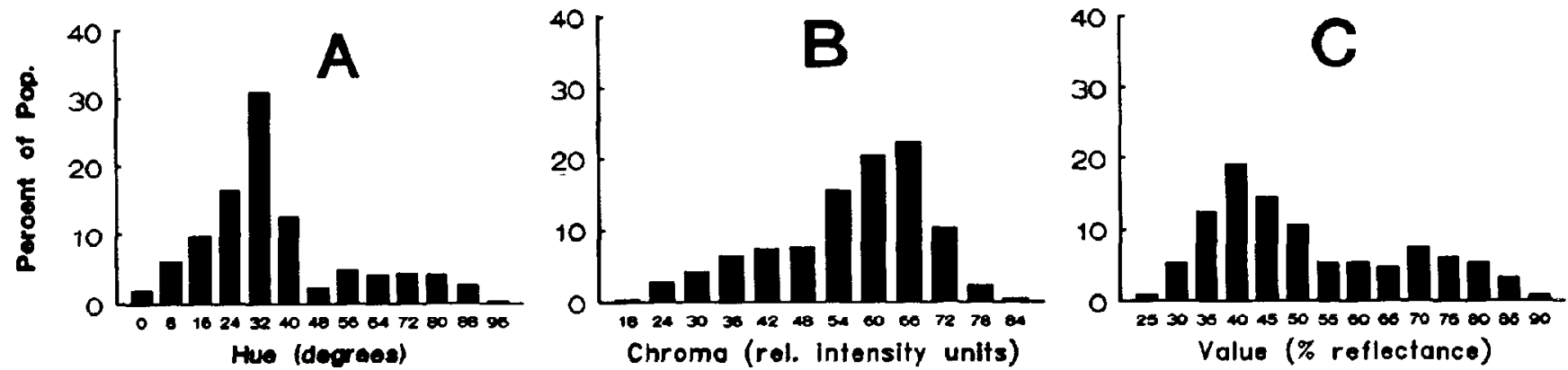

Fig. 1. Phenotypic distributions of ligule (A) hue, (B) chroma, and (C) value for generation 14 of the Davis gerbera population as a percentage of the total population $(n=437)$.

ber and again in April. Repeatabilities for hue, chroma, and value are defined as the correlations between these seasonal replicates. Statistical analysis was performed using the CHART and CORR procedures of PC-SAS (SAS, 1985).

The cvs for hue, chroma, and value were $<3 \%$ therefore, the instrument introduces little error into the overall assay.

The repeatabilities for hue, chroma, and value were $0.83,0.82$, and 0.86 , respectively. They indicate the constancy of flower color over a growing season as well as the heterogeneity for color of particular genotypes.

\section{Phenotypic distributions of color components}

The population's color distribution is described in terms of CIELAB notation (Fig. 1). Hue, value, and chroma all vary continuously throughout their ranges. They are broadly distributed and may be skewed or bimodal.

In the Davis population, hue is art angular measure that ranges from 0 to $100^{\circ}$ (viz., purplish red to yellow). The bimodal distribution of hue in Fig. 1A may be associated with the presence of two pigment systems: the red hues from anthocyanins and the yellow hues from carotenoids (Asen, 1984; Forkmann, 1991). The red hues represent more than threefourths of the population, and almost one-third is included within an $8^{\circ}$ interval centered at $32^{\circ}$. The yellow hues makeup less than onefourth of the population.

Chroma is a measure of an object's color intensity. The modifiers bright, strong, or deep indicate colors with high chroma. Pale, weak, or dark colors have low chroma. The distribution of chroma in Fig. 1B indicates a high proportion of the plants in this population have intensely colored flowers. This pattern supports the observation that vivid colors are generally considered a characteristic of gerbera.

Value measures the overall lightness of an object's color. Achromatic colors have neither hue nor chroma; they range through a series of grays from white to black as the proportion of total incident light reflected by a surface is decreased. Chromatic colors corresponding to the same scale of grays range from pale or bright to deep or dark. Interpretation of Fig. 1C suggests a bimodal distribution that may result from the dual action of the anthocyanin and carotenoid pigment systems. The yellows in the population tend to be lighter (reflect more of the total incident radiation) than reds and are less abundant. Consequently, it is expected that the dark or deep values will occur more frequently than the bright or pale values. The two-dimensional distributions of color components displayed in Fig. 2 demonstrate the pattern of covariability observed in this population. A strong relationship exists between value and hue ( $r=0.73$ ) (Fig. 2A), but not between chroma and hue ( $r=0.11)$ (Fig. 2b). The relationship between chroma and value $(r$ $=-0.35)$ becomes more apparent when the red hues $\left(0^{\circ}-50^{\circ}\right)$ (Fig. $2 \mathrm{C}$ ) are separated from the yellow hues $\left(50^{\circ}-100^{\circ}\right)$ (Fig. 2D)

An important feature of the data in Fig. 2A is the substantial variation in value $\left(\mathrm{L}^{*}\right)$ among the red hues. However, the yellow hues have only limited variation for value. This may reflect the increased opportunity for genetic

A

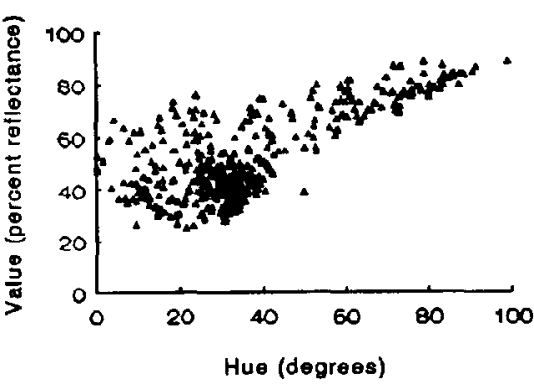

c

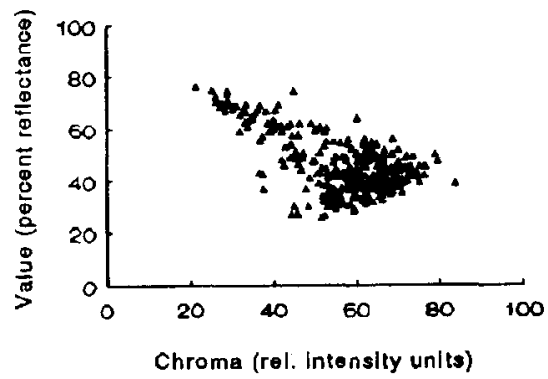

segregation provided by the complexity of the flavonoid pathway compared to the carotenoid pathway (Forkmann, 1991). The continuous change in the variability for value over the full range of hue may then result from the relative production of anthocyanins and carotenoids in common phenotypes. The greater value variation in the red hues may result from anthocyanin synthesis regulation. For example, in petunia (Petunia hybrida Vilm.), a gene controls the rate of anthocyanin synthesis, producing either light or dark red flowers (Gerats et al., 1982). When anthocyanin synthesis is limited, the accumulating precursors or metabolizes (such as dihydroflavonols) are colorless, resulting in an increase in the flower color value. Also, for the red hues, value is negatively correlated with chroma (Fig. 2C), which is expected if the value component of color were being determined by the rate of

Fig. 2. Two-dimensional distributions of ligule (A) hue and value, (B) hue and chroma, (C) chroma and value of hues $\left(0^{\circ}-50^{\circ}\right)$, and $(\mathrm{D})$ chroma and value of hues $\left(50^{\circ}-100^{\circ}\right)$ for generation 14 of the Davis gerbera population $(\mathrm{n}=437)$ 
anthocyanin synthesis. Further, flavonols (an alternate pathway of the anthocyanins) often act as copigments with anthocyanins, and together they make anthocyanins appear bluer (Asen et al., 1972). The greatest variability for value in Fig. $2 \mathrm{~A}$ is toward the blue end of the red range.

A different situation may describe the value variation in the yellow hues. They generally result from the carotenoid pathway (Griesbach, 1984a). The difference in value between yellow pigments and their precursors or alternate metabolizes may be small, resulting in only small fluctuations of the flower's value when pigment synthesis rates are varied. This fact is consistent with the data in Fig. 2D; increasing chroma (i.e., producing more pigment) has no effect on value.

Asen (1976) reviewed the effects of $\mathrm{pH}$, anthocyanin concentration, copigment : anthocyanin molar ratio, light intensity, temperature, and metals as factors contributing to variation in flower color. Griesbach (1984b) discussed the creation of novel flower colors by combining carotenoids and anthocyanins. The plethora of factors involved in determining flower color readily explains why ligule color is continuously distributed in the Davis population.

Breeding novel flower colors requires that the trait be defined so that objective and precise measurements can be obtained. Reflectance spectroscopy coupled with CIELAB notation allows the breeder to dissect color into three component traits that can be evaluated objectively and precisely. CIELAB notation defines color in terms that permit data to be treated as a continuous variable. Applying this technology to the Davis population suggests it may be advantageous to consider gerbera flower color as a complex trait that includes polygenic variation as well as the effects of major loci.

\section{Literature Cited}

Agoston, G.A. 1979. Color theory and its application in art and design. Springer-Verlag, New York.
Asen, S. 1976. Known factors responsible for infinite flower color variations. Acta Hort. 63:217223.

Asen, S. 1984. High pressure liquid chromatographic analysis of flavonoid chemical markers in petals from gerbera flowers as an adjunct for cultivar and germplasm identification. Photochemistry 23:2523-2526.

Asen, S., R. Stewart, and K. Norris. 1972. Copigmentation of anthocyanins in plant tissues and its effects on colour. Photochemistry 11:1139-1144.

Byrne, T.G., J. Harding, and R.L. Nelson. 1977. Greenhouse gerberas. Calif. Agr. 31(9):21-22.

Drennan, D., J. Harding, and T. Byrne. 1986. Heritability of inflorescence and floret traits in gerbera. Euphytica 35:319-330.

Ennos, R.A. and M.T. Clegg. 1983. Flower color variation in the morning glory, Ipomoea purpurea. J. Hered. 74:247-250.

Epperson, B.K. and M.T. Clegg. 1988. Genetics of flower color polymorphism in the common morning glory (Ipomoea purpurea). J. Hered. 79:6468.

Fernandez, R.N. and D.G. Schultze. 1987. Calculation of soil color from reflectance spectra. Amer. J. Soil Sci. 51:1277-1282.

Forkmann, G. 1991. Flavonoids as flower pigments: The formation of the natural spectrum and its extension by genetic engineering. Plant Breeding 106:1-26.

Francis, F.J. 1952. A method of measuring the skin color of apples. Proc. Amer. Soc. Hort. Sci. 81:408-414.

Francis, F.J. 1980. Color quality of horticultural crops. HortScience 15:14-15.

Gerats, A.G.M, R.T.J. Cornelissen, J.M.W Hogervost, A.W. Schram, and F. Bianchi. 1982. A gene controlling rate of anthocyanin synthesis and mutation frequency of the gene Anl in Petunia hybrida. Theoretical \& Applied Genet. 62:199-203.

Griesbach, R.J. 1984a. Biochemistry of flower color. Proc. 11th World Orchid Conf., Miami, Fla. p. 174-176.

Griesbach, R.J. 1984b. Effects of carotenoid-anthocyanin combinations on flower color. J. Hered. 75: 145-147.

Harding, J., J.D. Drennan, and T.G. Byrne. 1985. Components of genetic variation in the Davis population of gerbera. Euphytica 34:759-767.

Harding, J., H. Huang, and T. Byrne. 1991. Maternal, paternal, additive, and dominance compo- nents of variance in gerbera. Theoretical \& Applied Genet. 82:756-760.

Hayes, C.F., H.T.G. Chingon, and H.G.C. Young. 1988. Hunter b color measurements of papaya using a two-filter system. HortScience 23:399.

Huang, H., J. Harding, and T. Byrne. 1992. The effects of inbreeding on flower yield in gerbera. HortScience 27:586. (Abstr.)

Hunter, R.S. and R.W. Harold. 1987. The measurement of appearance. 2nd ed. Wiley, New York.

Ladd, D.L., M.L. Albrecht, and C.D. Clayberg. 1984. Genetics of flower color in spider flower. J. Amer. Soc. Hort. Sci. 109:759-761.

Lawrence, W.J.C. 1950. Genetic control of biochemical synthesis as exemplified by plant genetics-Flower colours, p. 3-9. In: R.T. Williams (ed.). Biochemical aspects of genetics. Biochem. Soc. Symp. no. 4, Westminster Medical School Hospital, London, 12 Feb. 1949. Cambridge Univ. Press, Cambridge, England.

Lawrence, W.J.C. and J.R. Price. 1940. Genetics and chemistry of flower colour variation. Biol. Rev. Cambridge Philosophical Soc. 15:35-58.

McLaren, K. 1976. The development of the CIE $1976\left(\mathrm{~L}^{*} \mathrm{a}^{*} \mathrm{~b}^{*}\right)$ uniform colour space and colourdifference formula. J. Soc. Dyers \& Colourists 92:338-341.

McLaren, K. and B. Rigg. 1976. The SDC recommended colour-difference formula Change to CIELAB. J. Soc. Dyers \& Colorists 92:337338.

Negi, S.S. and S.P.S. Raghaven. 1990. Genetics of flower color in China aster (Callistepus chinensis (L. Nees)). Euphytica 48(2): 117-122.

Nieuwhof, M., J.P. van Eijk, P. Keijzer, and W. Eikelboom. 1988. Inheritance of flower pigments in tulip (Tulipa L.). Euphytica 38:49-55.

Onslow, M.W. 1925. The anthocyanin pigments of plants. Cambridge Univ. Press, London.

SAS Institute. 1985. SAS user's guide: Basics, version 5 edition. SAS Institute, Cary, N.C.

Shaw, D.V. 1991. Genetic variation for objective and subjective measures of fresh fruit color in strawberries. J. Amer. Soc. Hort. Sci. 116:894898.

Vandoni, G.C. 1977. Genetic analysis of some phenotypes of Gerbera jamesoni. Genet. Agr. 31:113-119.

Yu, Y., T. Byrne, and J. Harding. 1991. Quantitative genetic analysis of flowering time in the Davis population of gerbera. I. Components of genetic variance and heritability. Euphytica 53:19-23. 